\title{
REPRESENTAÇÃO DISCURSIVA DE PESSOAS EM SITUAÇÃ̃O DE RUA NO "CADERNO BRASÍLIA”: NATURALIZAÇÃO E EXPURGO DO OUTRO
}

\begin{abstract}
Viviane de Melo Resende
Resumo: Neste artigo, utilizo o referencial da Análise de Discurso Crítica para analisar o texto "Abandono no Lago Norte - Casa que pertence ao Ibama virou ponto de drogas e abrigo para moradores de rua", publicado em janeiro de 2011 no "Caderno Brasília", semanário ligado ao jornal Hoje em Dia distribuído gratuitamente em centenas de pontos de Brasília. O texto discute o abandono de um imóvel público e suas consequências para a viżinhança, faz̧endo referência, inclusive no subtítulo, a "moradores de rua". Tomando esse objeto analítico, procedo à análise da representação de atores sociais, especificamente do grupo classificado como "moradores de rua". Também analiso, do ponto de vista da oração como representação, como esse grupo aparece no Sistema de Transitividade, com base nas orações em que o grupo é representado. A análise aponta que a situação de rua, grave problema social contemporâneo, é naturalizada na representação do evento em foco no texto.

Palavras-chave: Análise de Discurso Crítica. Representação. Transitividade. Naturalização. Situação de rua.
\end{abstract}

\section{INTRODUÇÃO}

A situação de rua é um grave problema social, com consequências desastrosas sobre as vidas de milhões no mundo (ONU, 2011). Entretanto, o problema vem sendo naturalizado, apagado ou distorcido em diversos textos publicados nos jornais ou transmitidos em outros veículos midiáticos (PARDO ABRIL, 2008; SILVA, 2009).

Neste trabalho, apresento uma análise discursiva da representação de pessoas em situação de rua no texto "Abandono no Lago Norte Casa que pertence ao Ibama virou ponto de drogas e abrigo para moradores de rua", publicado em janeiro de 2011 no "Caderno Brasília". Com tiragem de 20 mil exemplares, o "Caderno Brasília" é um encarte de domingo do jornal Hoje Dia, além de ser distribuido gratuitamente em cerca de 300 pontos de Brasília, como teatros, cinemas, bares, restaurantes, padarias e hotéis.

\footnotetext{
* Universidade de Brasília, professora adjunta, doutora em Linguística, área de concentração Linguagem e Sociedade. Email: viviane.melo.resende@gmail.com.
} 
Tomando por referencial teórico-metodológico a Análise de Discurso Crítica (FAIRCLOUGH, 2003; RAMALHO; RESENDE, 2011) e a Linguística Sistêmica Funcional (HALLIDAY, 2004), associada aos modos de operação da ideologia propostos por Thompson (2002) e à teoria da representação de atores sociais de van Leeuwen (2008), procedo à análise do referido texto, buscando especificamente lançar luz sobre a naturalização da situação de rua e seus efeitos potenciais.

Para discutir essas questões, organizo o artigo em quatro seções. $\mathrm{Na}$ primeira, abordo o referencial teórico-prático que orienta minha análise. Em seguida, na segunda seção, faço apontamentos acerca da precariedade social e da situação de rua em particular, focalizando a Red Latinoamericana de Análisis Crítico del Discurso de las personas sin techo y en extrema pobreza como locus privilegiado para a discussão do tema. $\mathrm{Na}$ terceira seção, contextualizo o objeto analítico em foco e discuto a estrutura genérica do texto. Na quarta, apresento uma análise discursiva crítica do texto em foco, tomando por base a representação de atores sociais, a transitividade e os modos de operação da ideologia. Por fim, teço algumas considerações finais.

\section{FUNCIONAMENTO SOCIAL DA LINGUAGEM E ANÁLISE DISCURSIVA CRÍTICA}

Em minhas pesquisas, tenho privilegiado a abordagem dos estudos do discurso conhecida como Análise de Discurso Crítica (ADC), especialmente a versão de ADC que dialoga com o Realismo Crítico. Por outro lado, prezo a Análise de Discurso Textualmente Orientada. Essa dupla articulação significa que, em termos teóricos, filio-me à perspectiva de funcionamento da sociedade proposta no Realismo Crítico (BHASKAR, 1989, 1998; ARCHER, 2000; entre outros), e procuro articular essa ontologia ao funcionamento social da linguagem; e em termos metodológicos, procuro realizar análises textualmente orientadas, ou seja, a explanação de problemas sociodiscursivos é fundamentada nos dados textuais. Acredito que pesquisas discursivas críticas devem utilizar a Linguística como ferramenta, mas para abordar problemas de caráter social - isso significa que a exposição de conhecimento em Linguística, em descrições minuciosas de textos, não se justifica se não lançar luz sobre problemas sociais implicados em relações de poder. 
A ADC é considerada 'crítica' porque sua abordagem é relacionaldialética, ou seja, é orientada para a compreensão dos modos pelos quais o elemento discursivo funciona na prática social, especificamente no que se refere a seus efeitos em lutas hegemônicas (RAMALHO; RESENDE, 2011). Uma teoria do funcionamento social da linguagem não pode deixar de considerar teorias do funcionamento da sociedade - e uma questão crucial, quando se focaliza a mudança social, é a questão da relação entre estrutura e ação, ou entre sociedade e indivíduo.

Para discutir isso, o Realismo Crítico, com seu Modelo Tranformacional da Atividade Social, é muito útil (RESENDE, 2009a). De acordo com esse modelo, a sociedade provê as condições para a ação humana, mas só existe nas ações humanas, que sempre utilizam alguma forma preexistente de ordem social (BHASKAR, 1998). Essa assimetria temporal entre estrutura e ação implica que sua relação não é entre equivalentes, o que leva a uma entidade organizacional intermediária: o sistema posição-prática. Essa ontologia do RC pode ser aplicada à organização social do potencial semiótico: no nível de abstração das estruturas sociais, temos os sistemas semióticos, a exemplo das línguas; no nível de concretude da ação social, temos os textos, materialização de nossas ações discursivas; e como entidades organizacionais intermediárias temos as ordens de discurso e seus elementos constituintes - gêneros, discursos e estilos (FAIRCLOUGH, 2003). Essa abordagem nos permite focalizar, em termos discursivos, não as línguas em si, nem os textos isoladamente, mas os tipos de relação que se estabelecem entre estrutura e ação discursiva em contextos específicos, ligados às posições ocupadas nas práticas desempenhadas (RAMALHO; RESENDE, 2011).

A versão de ADC de Fairclough estabelece diálogo com a Ciência Social Crítica, ou seja, questiona aspectos morais da vida social, associados ao discurso. A proposta de análise de problemas sociais pela lente do discurso se sustenta porque a relação entre discurso e sociedade é entendida como uma relação de constituição mútua. Isso porque a organização do potencial semiótico é articulada à organização potencial da sociedade. Nessa versão de ADC, o discurso é entendido como um elemento das práticas sociais em relação com outros elementos, ou seja, o discurso interioriza outros elementos das práticas, tais como as relações sociais, as atividades materiais etc. 
Essa conceituação complexa da relação entre linguagem e sociedade é, parece-me, o mais importante aspecto da Teoria Social do Discurso porque permite entender na sociedade a organização do potencial para significação no discurso, e no discurso compreender e explicar problemas sociais. Por isso os problemas que orientam as pesquisas nesse campo são problemas sociais, dos quais nos acercamos pela via do discurso. A relação entre as funções da linguagem e a organização do sistema linguístico é, para a Linguística Sistêmica Funcional (LSF), um aspecto geral da linguagem humana. A variação funcional não é uma seleção de usos da linguagem, e sim uma propriedade básica. Halliday teorizou três macrofunções que atuam simultaneamente em textos: ideacional, interpessoal e textual. A função ideacional da linguagem é sua função de representação da experiência; a função interpessoal refere-se a sua função no processo de interação social; e a função textual refere-se a aspectos semânticos, gramaticais e estruturais dos textos. Todo texto é multifuncional: as estruturas linguísticas não 'selecionam' funções específicas isoladas para desempenhar; expressam de forma integrada todos os componentes funcionais do significado.

Em 1992, em Discourse and social change, Fairclough sugeriu a cisão da função interpessoal de Halliday em duas funções separadas, a função identitária e a função relacional. A função identitária da linguagem "relaciona-se aos modos pelos quais as identidades sociais são estabelecidas no discurso"; e a função relacional refere-se a "como as relações sociais entre os participantes do discurso são representadas e negociadas" (FAIRCLOUGH, 2001, p. 92). Em 2003, em Analysing discourse, Fairclough ampliou o diálogo teórico entre a ADC e a LSF, propondo uma articulação entre as macrofunções de Halliday e os conceitos de gênero, discurso e estilo, sugerindo três principais tipos de significado no discurso: o significado acional, o significado representacional e o significado identificacional.

Como discutimos em Resende e Ramalho (2006), a operacionalização dos três significados mantém a noção de multifuncionalidade presente na LSF: Fairclough enfatiza que os três atuam simultaneamente em todo texto. Nas práticas sociais, o discurso figura de três principais maneiras: como modos de agir, como modos de representar e como modos de ser, e a cada uma delas corresponde um 
tipo de significado: acional, representacional e identificacional. A relação entre os três níveis de significados é interna, ou seja, há fluxo entre os três. Além disso, Fairclough (2003) teoriza as noções de gênero, discurso e estilo - respectivamente associadas aos significados acional, representacional e identificacional - como os três principais elementos das ordens de discurso, relacionadas aos diferentes campos da atividade humana.

Neste artigo, o foco é o significado representacional: o interesse é explorar os modos como grupos considerados 'incômodos' em uma vizinhança de classe média alta são representados no texto selecionado como objeto analítico. Os modos de representação dos grupos assimilados como "moradores de rua" não são criação individual do texto em foco; ao contrário, esse texto materializa discursos socialmente disponíveis, como modos relativamente estáveis de representação, que são no texto materializados e postos em funcionamento, com efeitos sociais potenciais, já que todo texto é efeito de práticas e eventos específicos, mas também tem efeitos sobre a sociedade.

Se nos afastarmos um pouco da teorização sobre o funcionamento social da linguagem para abordar os procedimentos materiais da análise, outro aspecto fundamental da ADC é que a análise discursiva deve ser textualmente orientada. Isso significa que utilizamos um arcabouço analítico que nos provê diversas categorias de análise, e essas categorias devem ser sistematicamente aplicadas aos corpos de textos que são nossos dados. Análise de discurso não é leitura nem é comentário, é trabalho sistemático de aplicação de categorias que nos permitem a crítica explanatória porque essas categorias estão associadas a conceitos teóricos e a uma teorização complexa do funcionamento da linguagem na sociedade. Neste artigo, as categorias utilizadas para a análise linguístico-discursiva são o Sistema de Transitividade, desenvolvido na Linguística Sistêmica Funcional (HALLIDAY, 2004), e a Representação de Atores Sociais, enquadre analítico proposto por van Leeuwen $(1997,2008)$.

Alexandre e Resende (2010, p. 94) explicam que o Sistema de Transitividade 
é o mecanismo léxico-gramatical através do qual se constrói a experiência como um mundo feito de processos, participantes e circunstâncias ( $c$. Halliday, 2004, p. 168ss). O fluxo de acontecimentos que experienciamos é, por assim dizer, retalhado em vários pedaços, e cada um desses pedaços é moldado como uma figura - uma figura de acontecer, de fazer, de sentir, de dizer, de ser ou de ter. Cada figura assenta, pois, num tipo específico de processo, ao qual se associam determinados participantes e que pode eventualmente ser ampliado por circunstâncias.

Mais concretamente, a gramática da experiência, tal como teorizado em LSF, assenta numa tipologia de processos [...] que abarca três tipos principais de processos, correspondentes às zonas das cores primárias, e três tipos secundários de processos, correspondentes às zonas das cores secundárias. Os tipos principais de Processos são: Relacional, Mental e Material. Os tipos secundários de Processos são: Verbal, Comportamental e Existencial.

$[\ldots]$

A gramática da experiência é concebida como um contínuo, com zonas nucleares e zonas intermediárias, situando-se nas primeiras os exemplos prototípicos de cada tipo de processo. A existência de zonas intermediárias mostra que "os termos sistêmicos não são categorias aristotélicas. Em vez disso são categorias difusas" (Halliday, 2004, p. 174, nota de rodapé). Cada um desses seis tipos principais de processos corresponde a uma configuração particular: "alguém é/significa algo", "alguém fala/verbaliza algo", "alguém pensa/sente algo", "alguém respira/tosse", "alguém faz algo a alguém/cria algo" e "alguém existe/há algo" (cf. Gouveia, 2009, p. 33). Cada uma destas configurações combina diferentes tipos de entidades, i.e., participantes e, como tal, constrói diferentes significados.

No texto "Abandono no Lago Norte - Casa que pertence ao Ibama virou ponto de drogas e abrigo para moradores de rua", a tecnologia analítica do Sistema de Transitividade será aplicada apenas às orações em que estão representados os grupos sociais construídos como 'problema' e associados à situação de rua. Os mesmos excertos textuais serão analisados também com base no referencial da Representação de 
Atores Sociais. Segundo esse arcabouço, os atores ou grupos sociais envolvidos em eventos e práticas sociais e as relações estabelecidas entre eles podem ser analisados, em textos e interações, de um ponto de vista representacional, em termos de que atores e atividades são incluídos ou excluídos na representação, e a que atores e atividades incluídos é dada proeminência.

Van Leeuwen (1997) esboça um inventário sociossemântico dos modos pelos quais atores sociais podem ser representados, discutindo a relevância sociológica das categorias apresentadas e sua realização linguística. Os diversos modos pelos quais atores sociais podem ser representados em textos podem ser vistos como uma questão também gramatical se, como Halliday (2004), entendemos a gramática como um 'potencial de significados' cuja realização concreta se dá pelas escolhas operadas por falantes. As maneiras pelas quais atores sociais são representados em textos podem indicar posicionamentos em relação a eles e a suas atividades - por exemplo, determinados atores podem ter sua agência ofuscada ou enfatizada em representações, podem ser referidos de modos que presumem julgamentos acerca do que são ou do que fazem. Resulta que a análise de tais representações pode ser útil para a investigação da construção discursiva de identificações e relações sociais em textos e interações.

Em primeiro lugar, as representações podem incluir ou excluir atores sociais, servindo a interesses e propósitos em relação a quem se dirigem. Algumas exclusões podem simplesmente se referir a pormenores que se assume que os/as interlocutores/as já conheçam, ou que são considerados irrelevantes, outras podem estar relacionadas a uma estratégia de ofuscação de sua responsabilidade na ação ou de sua atividade. Uma vez incluídos em representações, atores sociais podem ser ativados ou apassivados. $\mathrm{Na}$ ativação, são representados como forças dinâmicas numa atividade. A ativação de atores sociais pode se realizar de maneira clara, por meio dos papéis gramaticais participantes em estruturas transitivas. Para van Leeuwen (1997, p. 185; acréscimos meus), a relevância dos papéis gramaticais ("quem é representado como 'agente' [Ator], e como 'paciente' [Meta] no que diz respeito a uma dada ação”) em representações decorre de que "não é necessário que haja congruência entre os papéis que desempenham, de fato, em práticas sociais e os papéis gramaticais que lhes são atribuídos nos textos. As 
representações podem redistribuir papéis e organizar as relações sociais entre os/as participantes". Isso mostra a relação entre o Sistema de Transitividade e a Representação de Atores Sociais - a transitividade pode ser entendida como parte do potencial metodológico para análise de representação de atores sociais em textos.

$\mathrm{Na}$ apassivação, os atores sociais são representados como "submetendo-se à atividade ou como sendo receptores dela" (FAIRCLOUGH, 2003, p. 145). A questão é verificar se a agência em eventos é clara ou ofuscada, se a apassivação de atores na representação discursiva ofusca sua responsabilidade em eventos ou seu papel em relações sociais.

Atores sociais podem ser representados como classes, por meio de uma generalização, ou como indivíduos identificáveis, por meio de uma especificação. Atores sociais representados especificamente podem ser representados por seus nomes próprios (nomeação) ou pela função que desempenham na prática ou no evento social (categorização). Funcionalização e identificação são dois tipos fundamentais de categorização. $\mathrm{Na}$ funcionalização, os atores sociais são representados em termos de uma atividade, uma ocupação ou uma função. $\mathrm{Na}$ identificação, os atores sociais são definidos não em termos do que fazem, mas em termos do que são. Um tipo de identificação é a classificação, em que atores sociais são referidos em termos das principais categorias através das quais uma dada sociedade ou instituição diferencia classes de pessoas (idade, sexo, origem, classe social etc.).

Embora van Leeuwen tipifique a categorização (representação pela função desempenhada na prática) como um tipo de especificação - isto é, como uma possibilidade de representação de atores reconhecidos como indivíduos identificáveis -, os dados aqui explorados mostram que grupos respresentados por generalização (não como indivíduos específicos, mas como grupo) também podem ser categorizados. Isso acontece quando o significado ativado para a representação do grupo refere-se a sua atividade, ocupação ou função.

Nem sempre, em representações, atores sociais são referidos como pessoas: podem ser representados também de maneira impessoal. Atores sociais podem, então, ser impersonalizados, por meio de substantivos abstratos ou substantivos concretos cujo significado não 
inclui a característica semântica [+ humano]. Há, segundo van Leeuwen, dois tipos de impersonalização: a abstração e a objetivação. No caso da abstração, os atores sociais são representados por meio de uma qualidade a eles atribuída na representação ${ }^{1}$; na objetivação, são representados por meio de referência a um local ou a algo diretamente associado a sua pessoa ou a sua atividade, por referência metonímica ao local em que desempenham suas atividades, a seus enunciados, a seus instrumentos de trabalho.

As categorias levantadas por van Leeuwen $(1997,2008)$ acerca da representação de atores sociais em textos são numerosas, inclusive ultrapassando as supramencionadas, e nem todas mostram-se relevantes para a análise que proponho aqui. Por isso, simplifico o arcabouço, de acordo com meus interesses específicos neste artigo, e utilizo um quadro de categorias selecionado para o texto em foco, tendo em vista especificamente a representação do grupo associado à situação de rua e à ocupação do imóvel.

\section{SITUAÇÃO DE RUA E ANÁLISE DISCURSIVA}

A naturalização da situação de rua, que deixa de ser percebida como um problema, e o expurgo de pessoas em situação de rua, que são representadas como categoria a ser apartada e expurgada da sociedade, são problemas sociais parcialmente discursivos porque a representação discursiva da situação de rua, por exemplo na mídia, influencia os modos como percebemos e reagimos à precariedade social, e os modos como identificamos pessoas em situação de rua e nos identificamos em relação ao problema. Por outro lado, e como a relação entre linguagem e sociedade é de mão dupla, essas mesmas representações, materializadas em textos midiáticos, também são efeitos de práticas e relações sociais, isto é, estão plasmadas em estruturas prévias.

De acordo com a Organização das Nações Unidas, há hoje, em todo o mundo, cerca de 100 milhões de pessoas nas ruas, 600 milhões vivendo em abrigos, e mais de um bilhão em moradias sem condições dignas (ONU, 2011). Não obstante, “a crise global das pessoas em

\footnotetext{
${ }^{1}$ O exemplo fornecido por van Leeuwen (1997, p. 208) é "a maneira como os migrantes 'pobres, negros, não-qualificados, muçulmanos ou ilegais' são referidos através do termo 'problemas' - está a ser-lhes atribuída a qualidade de serem problemáticos, e esta qualidade é usada para os designar".
}

RESENDE - Representação discursiva de pessoas... 
situação de rua é não apenas comum, mas também ignorada, despercebida ou mal compreendida" (INSP, 2011). É nesse sentido que Mattos e Ferreira (2004, p. 47-8) apresentam suas reflexões a respeito das representações sociais que se constroem acerca da pessoa em situação de rua (como "vagabunda, louca, suja, perigosa ou digna de piedade"):

Alguns as vêem como perigosas, apressam o passo. Outros logo as consideram vagabundas e que ali estão por não quererem trabalhar, olhando-as com hostilidade. Muitos atravessam a rua com receio de serem abordados por pedido de esmola, ou mesmo por pré-conceberem que são pessoas sujas e mal cheirosas. Há também aqueles que delas sentem pena e olham-nas com comoção ou piedade. [...] Habituados com suas presenças, parece que estamos dessensibilizados em relação à sua condição. [...]

Observa-se, assim, a existência de representações sociais pejorativas, em relação à população em situação de rua, que se materializam nas relações sociais. Estes conteúdos interferem na constituição da identidade destas pessoas: é conhecimento socialmente compartilhado e utilizado como suporte para a construção de suas identidades pessoais. Trata-se de conteúdos simbólicos de cunho ideológico, na medida em que favorecem a cristalização de relações de exploração e dominação.

Além de impactarem as identidades pessoais e sociais, essas representações, muitas vezes repetidas em diferentes tipos de textos, também têm efeitos potenciais nos modos como agimos em relação à situação de rua. Nesse contexto, pessoas extremamente pobres passam a ser consideradas economicamente desnecessárias, porque a industrialização reduz a necessidade de trabalhadores/as, sobretudo aqueles/as considerados/as 'desqualificados/as'; socialmente incômodas, "por causa da degradação urbana provocada pela pobreza"; e politicamente ameaçadoras, uma vez que a exclusão de parcela significativa da sociedade acarreta situações de desordem social (BUARQUE, 2003, p. 32). Ser considerado/a desnecessário/a, incômodo/a e ameaçador/a muitas vezes implica tornar-se também passível de eliminação, simbólica ou mesmo física. De acordo com Nascimento (2003, p. 62), "estes grupos sociais passam a 'não ter direito 
a ter direitos", ou seja, sua condição de privação de direitos reconhecidos para outros grupos é naturalizada, passa a não ser percebida como um problema de injustiça (DEJOURS, 2003).

Para Thompson (2002), a naturalização é uma estratégia de construção simbólica, ligada à reificação, pela qual criações sociais são representadas como acontecimentos naturais. $\mathrm{O}$ expurgo do outro, por seu turno, é uma estratégia de construção simbólica de fragmentação em que indivíduos ou, no caso do texto analisado, grupos são representados como inimigos que devem ser combatidos, apartados, expurgados. Como sabemos, a construção de identidades e de identificações também está ligada aos processos representacionais de classificação, de elaboração de semelhanças e diferenças (FAIRCLOUGH, 2003). Além disso, a classificação influencia os modos como as pessoas agem e pensam sobre uma dada situação, por isso a preocupação com a questão da representação de atores sociais em contextos de desigualdade e precariedade social é essencial.

Por meio de classificações que legitimam a diferença, a injustiça social é naturalizada e deixa de ser questionada como injustiça, passando a ser compreendida como um estado natural de coisas (RESENDE, 2009b). Isso pode ter o efeito de destituir grupos em situação de precariedade de sua condição essencial de sujeitos de direitos, e de minar suas possibilidades de articulação e resistência. Tendo isso em foco, em 2005, no congresso da Associação Latino-Americana de Estudos do Discurso (ALED), em Santiago do Chile, foi fundada a Red Latinoamericana de Análisis Crítico del Discurso de las personas sin techo y en extrema pobreza (REDLAD), com o objetivo de estudar a representação de situações de extrema pobreza nos países membros. Desde então, a rede tem-se reunido anualmente para discussão e intercâmbio das pesquisas realizadas. Além do livro El discurso sobre la pobreza en América Latina, organizado por Laura Pardo (2008b), a rede também produziu outros trabalhos coletivos, como o número monográfico da revista Discurso \& Sociedad, também organizado por Laura Pardo (2008b), e o livro Discurso, pobreza y exclusión en América Latina, editado por Lésmer Montecino (2010). E também devem ser mencionados os livros de Neyla Pardo (2007, 2008), especialmente seu livro ¿Que nos dicen? ¿Que vemos? ¿Que és... pobreza?.

RESENDE - Representação discursiva de pessoas... 
A REDLAD é um exemplo produtivo da ampliação do potencial de analistas de discurso quando trabalham em rede, mas para além disso tem se mostrado também excelente espaço para reflexão teórica e metodológica. Minhas próprias pesquisas tiram partido disso.

\section{O TEXTO “ABANDONO NO LAGO NORTE - CASA QUE PERTENCE AO IBAMA VIROU PONTO DE DROGAS E ABRIGO PARA MORADORES DE RUA"}

O texto publicado no "Caderno Brasília" aborda a seguinte questão: uma casa, pertencente a órgão público, localizada em bairro residencial de classe média alta, encontrava-se abandonada havia cerca de dois anos e passou a trazer uma série de 'problemas para a vizinhança'. Entre os problemas destacados no texto, ressaltam-se a insegurança, o risco de proliferação do mosquito da dengue e a presença de grupos que não eram bem-vindos no local, assimilados no subtítulo da matéria pelo rótulo "moradores de rua".

Se pensarmos na estrutura genérica do texto em questão, veremos que se trata de uma notícia jornalística. Fairclough (2003, p. 32-3) conceitua 'gêneros de governança' como aqueles associados a redes de práticas especializadas na regulação ou no controle de outras práticas sociais. São caracterizados por "propriedades específicas de recontextualização" que incluem "um movimento de apropriação, transformação e colonização" - a apropriação de elementos de uma prática social em outra, com a transformação da primeira de modos particulares associados à colonização especializada da prática reguladora. Fairclough toma as notícias veiculadas pela mídia como exemplo de materialização de gênero de governança, associando-as aos meios de comunicação que integram o "aparato de governança" e podem controlar os eventos noticiados, quando os recontextualizam. Trata-se de regulação porque os modos como fatos são noticiados podem influenciar as maneiras como as pessoas reagem aos eventos. A notícia em questão, por exemplo, pode orientar crenças sobre a pobreza extrema e a situação de rua em particular, identificando grupos sociais sob o rótulo "moradores de rua" e classificando-os como indesejáveis, problemáticos, perigosos, desagradáveis. 
Pelo potencial do gênero 'notícia', espera-se um texto predominantemente narrativo e articulando também instâncias de discurso relatado e de comentário. De fato, na primeira parte do texto, predominam os verbos no passado, tempo nuclear do mundo narrado a exceção é o primeiro período do texto ("Uma casa abandonada há mais de dois anos no Lago Norte chama a atenção de quem passa no local e causa problemas aos moradores da região"). Na primeira parte do texto, a autora traz as informações sobre o caso, noticia o evento. Os cinco parágrafos que compõem essa primeira parte concentram-se na narrativa da transformação do espaço em consequência do abandono do imóvel e sua posterior ocupação. Trata-se de demarcar a diferença entre dois tempos, e isso se texturiza por meio de processos como 'virar', 'transformar', 'passar', que denotam mudança de estado. Até aqui, o texto reconstrói a história noticiada, com foco no incômodo acarretado para a vizinhança e nas tentativas frustradas de resolução do problema, inclusive com ênfase na ação de um político particular. Esse foco é o que domina a primeira parte do texto.

$\mathrm{Na}$ segunda parte do texto, entretanto, têm destaque sequências textuais em que o tempo nuclear do mundo comentado - o presente, utilizado em estruturas de comentário - também se faz notar. Nessa parte, composta de quatro parágrafos, o foco não é noticiar o fato, mas apresentar comentários que incluem argumentação sobre o fato narrado. Nesses casos, predominam os comentários de moradores/as locais a respeito do incômodo e da insegurança causados pelo abandono do imóvel. É nessa parte da notícia que ganha maior ênfase o discurso relatado, em instâncias como, por exemplo, "indigna-se com a situação", "ser incomodado com a 'barulheira' durante a noite", "sente-se insegura na região".

A parte final do texto, como é de praxe em notícias dessa natureza, é dedicada à voz da autoridade policial e à enunciação de providências esperadas ou prometidas pelas autoridades responsáveis. Os dois primeiros parágrafos dessa parte final contêm a articulação da vOZ policial, e os dois últimos referem-se ao posicionamento do órgão público responsável pela casa abandonada em relação ao problema. A articulação da voz policial reserva-nos uma surpresa que deixaremos para o final. 
Vamos nos concentrar, então, nas duas primeiras partes do texto, e especificamente na representação dos grupos avaliados como indesejáveis na vizinhança e assimilados na manchete como "moradores de rua”. Aliás, como observação inicial acerca da representação do grupo assimilado, podemos verificar que ao longo dessas duas primeiras partes a referência ao grupo é o fio condutor do texto, estando ausente apenas nos trechos dedicados à enumeração de providências frustradas tomadas até o momento pelo deputado destacado no texto. O que nos interessa nesse exercício analítico é verificar os modos de representação do grupo classificado como problema. Os excertos em que é representado, nas duas primeiras partes do texto, são os seguintes (os grifos não estão no original):

\section{Quadro 1 - Excertos em que se representa o grupo, da manchete ao nono parágrafo.}

\begin{tabular}{|c|c|}
\hline Manchete & $\begin{array}{l}\text { Abandono no Lago Norte - Casa que pertence ao Ibama virou ponto de drogas e } \\
\text { abrigo para moradores de rua }\end{array}$ \\
\hline $\int 1$ & $\begin{array}{l}\text { A residência, localizada na QI 2, conjunto 11, casa 18, virou ponto de encontro de } \\
\text { usuários de drogas, prostitutas e meninos de rua. }\end{array}$ \\
\hline$\$ 4$ & $\begin{array}{l}\text { Logo após estes arquivos terem sido transferidos para a sede do Ibama, a casa ficou } \\
\text { abandonada e passou a atrair uma série de moradores de rua. }\end{array}$ \\
\hline $\int 6$ & $\begin{array}{l}\text { Além de ser incomodado com a "barulheira" durante a noite, ele relata que o ponto } \\
\text { virou também alvo de assalto e risco de dengue. }\end{array}$ \\
\hline $\int 7$ & $\begin{array}{l}\text { "Já liguei para a polícia mais de cinco vezes. Eles até vêm ao local e já prenderam } \\
\text { usuários de drogas. Mas, no outro dia, eles voltam." }\end{array}$ \\
\hline $\int 8$ & $\begin{array}{l}\text { Também moradora da quadra, a dona de casa Francisca Félix sente-se insegura na } \\
\text { região. Ela já presenciou vários assaltos e ouviu gritaria na casa ao lado. }\end{array}$ \\
\hline$\$ 9$ & $\begin{array}{l}\text { "Eles sentam no muro e ficam fazendo uma bagunça. Depois usam a caixa d'água } \\
\text { para tomar banho. E dá também prostitutas. Virou um perigo morar aqui”, frisa. }\end{array}$ \\
\hline
\end{tabular}

\section{Fonte: Elaboração própria.}

Desde a manchete até o final da segunda parte do texto, com a exceção de apenas dois parágrafos, o foco do texto é o grupo composto por "moradores de rua", "usuários de drogas", "prostitutas" e "meninos de rua". Note-se que todos esses atores são unificados pelo rótulo "moradores de rua" na manchete da matéria. Se é verdade que da manchete se depreende o tratamento dado à notícia, podemos dizer que esse texto refere-se ao abandono de um imóvel e a sua ocupação por "moradores de rua". 


\section{REPRESENTAÇÃO DOS 'GRUPOS INCÔMODOS' NAS DUAS PRIMEIRAS PARTES DO TEXTO "ABANDONO NO LAGO NORTE - CASA QUE PERTENCE AO IBAMA VIROU PONTO DE DROGAS E ABRIGO PARA MORADORES DE RUA"}

Tomando como objeto da análise os sete excertos destacados no Quadro 1, vejamos como se realiza a representação de atores sociais, tendo em vista o arcabouço de van Leeuwen $(1997,2008)$ e o Sistema de Transitividade (HALLIDAY, 2004). Comecemos pela manchete, reproduzida a seguir no Exemplo (1):

(1) Abandono no Lago Norte. Casa que pertence ao Ibama virou ponto de drogas e abrigo para moradores de rua.

Já na manchete, temos a representação do tipo generalização, quando atores sociais são representados como classe ("moradores de rua"). Ainda que não sejam representados como indivíduos identificáveis, os membros do grupo são categorizados por classificação, isto é, são representados com base na categoria de classe social, informação utilizada para definir o que são nessa representação.

Em termos da estrutura de Transitividade, o grupo proposicional "para moradores de rua" está dentro do grupo nominal ("ponto de drogas e abrigo para moradores de rua"). Quanto ao papel desempenhado pelo grupo social 'moradores de rua' nessa oração, podese dizer que estão muito escondidos gramaticalmente, profundamente inseridos na estrutura de encaixe. A estrutura oracional coloca em paralelo os elementos "ponto de drogas" e "abrigo para moradores de rua", e dessa relação decorre a avaliação de 'abrigo para moradores de rua' como algo negativo.

Já aí se esclarece que o "abandono” a que se refere a matéria é o abandono do imóvel, mas de nenhuma maneira o abandono de grupos sociais sem acesso a moradia - se esse fosse o foco, 'abrigo para moradores de rua' talvez tivesse conotação positiva. Mas não é o caso nesse texto. Passemos ao Exemplo (2): 
(2) A residência, localizada na QI 2, conjunto 11, casa 18, virou ponto de encontro de usuários de drogas, prostitutas e meninos de rua.

Se a generalização do grupo de pessoas referidas como 'moradores de rua' já aparecia na manchete, o grau daquela generalização é ainda mais percebido no primeiro parágrafo do texto. Esse parágrafo funciona como uma espécie de explicação da manchete: retoma a mesma informação, mas de maneira mais específica ou mais detalhada. Assim como "Casa" na manchete se recontextualiza no primeiro parágrafo como "A residência, localizada na QI 2, conjunto 11, casa 18" - o endereço completo e a informação de que se trata de imóvel em bairro residencial -, o grupo classificado simplesmente como "moradores de rua" na manchete também recebe aqui pormenores explicativos. O que lá era generalizado em um só grupo, aqui é categorizado como três grupos separáveis, ainda que assimiláveis na representação: "usuários de drogas, prostitutas e meninos de rua".

Nos dois primeiros casos, estamos diante de funcionalização, quando atores sociais são representados em termos de uma atividade (como usar drogas) ou uma ocupação (como a prostituição); no caso de "meninos de rua", temos uma categorização por classificação - o elemento que define a categoria, assim como em "moradores de rua", é o vínculo com a rua, o que remete à pobreza extrema e, portanto, a classe social. Nesse sentido, podemos dizer que essas categorizações, embora mantenham o traço humano pelo primeiro elemento das lexias "meninos" e "moradores" - têm seu elemento identificador em "de rua", o que aproxima essas representações da objetivação, quando, segundo van Leeuwen (1997), atores sociais são representados por referência a um local ou a algo associado a sua pessoa ou a sua atividade.

Em termos do Sistema de Transitividade, a oração no primeiro parágrafo é muito semelhante em estrutura à oração já analisada da manchete: temos um processo relacional em que ' $\mathrm{X}$ virou $\mathrm{Y}$ ', onde $\mathrm{X}$ é a "residência" e Y é "ponto de encontro de usuários de drogas, prostitutas e meninos de rua". Assim como na manchete, nessa oração o grupo "usuários de drogas, prostitutas e meninos de rua" está dentro do grupo nominal, inserido profundamente na estrutura de encaixe. 
Vejamos a oração do quarto parágrafo:

(3) Logo após estes arquivos terem sido transferidos para a sede do Ibama, a casa ficou abandonada e passou a atrair uma série de moradores de rua.

O que nos interessa aqui é o trecho "a casa ficou abandonada e passou a atrair uma série de moradores de rua". Temos novamente a generalização por classificação, com o mesmo vínculo a classe social e a mesma objetificação decorrente da ênfase a "de rua" na classificação. Nesse caso, a natureza genérica da representação é reforçada ainda pelo uso do pré-modificador "uma série de", que enfatiza o caráter não individualizado da representação - não importa quem são essas pessoas como indivíduos identificáveis, mas seu pertencimento a uma classe que pode ser referida como "uma série de" - semelhante a 'um bando de', 'um monte de'. O que se escolhe ressaltar, ao contrário da individualidade de cada membro do grupo representado, é sua quantidade, sua coletividade incômoda para os/as moradores/as do local, esses/as sim individualizados/as e nomeados/as no texto (ver a seguir).

Em termos da transitividade da oração, "uma série de moradores de rua" ocupa posição de Meta da atração exercida pelo abandono do imóvel, ou seja, assume um papel passivo, numa representação por apassivação. O problema enfatizado nessa oração e no texto é, portanto, o abandono do imóvel e sua consequência de 'exercer atração sobre'. O grupo de pessoas em situação de rua não seria questão, não fosse o fato de 'ser atraído' para o Lago Norte, bairro residencial de classe média alta, onde o grupo se torna "uma série de" incômodos.

No sexto parágrafo, que inicia a segunda parte do texto, a oração em análise é:

(4) Advogado e morador da quadra, na casa que fica bem em frente ao imóvel do Ibama, Fernando Cardoso indigna-se com a situação. Além de ser incomodado com a "barulheira" durante a noite, ele relata que o ponto virou também alvo de assalto e risco de dengue 
Nesse caso, estamos diante de uma instância de relato da fala de um morador da mesma rua, representado como "Fernando Cardoso" e como "Advogado e morador da quadra". Os verbos dicendi que introduzem sua vOz no texto são "indigna-se" e "relata". A escolha desses verbos de dizer acrescenta significados na representação. A escolha de "indigna-se" incide negativamente sobre o fato representado, que com base nisso poderia ser classificado como 'um absurdo' - o 'absurdo' no caso é, de novo, o abandono do imóvel, não a situação de rua como problema enfrentado por muitas pessoas em Brasília. O problema representado, na verdade, é o incômodo para a vizinhança, além dos riscos a sua segurança. Por sua vez, a seleção pelo verbo 'relatar' indica a condição de testemunha do senhor Fernando Cardoso, que por isso pode fazer um 'relato' de sua experiência e de sua indignação.

Quanto à representação do grupo 'moradores de rua' no parágrafo, estamos diante de algo distinto do que vimos até aqui. Ao contrário da representação como seres humanos - ainda que em grupo generalizado em que a individualidade não se põe em questão e com a objetivação decorrente do elemento identificador "de rua" -, nessa oração temos uma representação por impessoalização - o grupo é aqui representado pelas consequências de sua presença: incomodidade (“"barulheira' durante a noite”) e insegurança (“assalto"), o que remete ao que já vimos sobre pessoas em situação de rua serem consideradas um incômodo e uma ameaça (BUARQUE, 2003).

Em termos do Sistema de Transitividade, "com a 'barulheira' durante a noite" está em posição de circunstância, na periferia da oração, e a referência à insegurança, "assalto", é pós-modificador de "alvo", em outro processo relacional do tipo 'X virou Y'. Nesse sentido, pode-se dizer que o problema da insegurança para os/as moradores/as da região é mais central na estrutura da oração que o problema do incômodo, que se texturiza em posição circunstancial. De fato, uma boa parte dos textos que tratam da situação de rua na mídia tradicional o faz por meio de um discurso da insegurança, que, como aqui, reconhece o ponto nodal do problema não na condição de privação de direitos dos grupos que enfrentam a situação de rua, mas em grupo sociais que reconhecem esses 'outros' como um problema a ser combatido (RESENDE, 2009b). 
Vejamos o que consta no sétimo parágrafo do texto, reproduzido integralmente a seguir:

(5) "Já liguei para a polícia mais de cinco vezes. Eles até vêm ao local e já prenderam usuários de drogas. Mas, no outro dia, eles voltam. O Ibama deveria tomar alguma providência até mesmo porque a piscina está parada e é atrativo para o mosquito da dengue", revolta-se.

O trecho em destaque é também relato de fala do mesmo Fernando Cardoso. Nesse caso, o verbo dicendi selecionado é "revoltase", de efeito semelhante ao de "indigna-se" no caso anterior. A referência ao grupo que 'incomoda' a vizinhança é, novamente, uma representação a grupo categoriz̧ado por funcionalização - a identificação aqui, como no caso do Exemplo (2), realiza-se em termos da atividade do consumo de drogas. Em seguida, a retomada do mesmo grupo dá-se por pronominalização, com "eles". O foco no problema é o incômodo - a questão não é que façam uso de drogas, mas que 'voltem' a fazê-lo naquele local.

No primeiro caso, o grupo de "usuários de drogas" é, na oração, Meta da ação de 'prender', cujo Ator é a polícia, representada por meio da primeira ocorrência do pronome "Eles". No segundo caso, "eles" (retomada anafórica de "usuários de drogas") funciona como Ator da ação de 'voltar'. Note-se que essa é a primeira ocorrência de representação de papel ativo para o grupo nas estruturas oracionais analisadas, e trata-se simplesmente da ação de voltar ao local onde o grupo é um incômodo, aspecto enfatizado em todo o texto. Nesse sentido, pode-se dizer que a representação do grupo no texto tende para a identificação, em que pese a contradição de sua individualidade não ser posta em relevo. Em todo caso, o grupo é representado por identificação no sentido de que esses atores sociais "são definidos não [apenas] em termos do que fazem, mas [principalmente] em termos do que, mais ou menos permanentemente, ou inevitavelmente, são" (VAN LEEUWEN, 2008, p. 42, acréscimos meus).

É claro que ser 'usuário de droga' inclui a ação de usar drogas, mas não é essa ação que é enfatizada na estrutura textual - compare-se, 
por exemplo, com a representação possível de 'eles vêm aqui e usam drogas' -, em que não são representados como agindo no mundo, mas como sendo simplesmente. Ser "usuários de drogas" assume natureza mais essencialista; é o que identifica.

No parágrafo seguinte, o trecho destacado é o seguinte:

(6) Também moradora da quadra, a dona de casa Francisca Félix sente-se insegura na região. Ela já presenciou vários assaltos e ouviu gritaria na casa ao lado.

O trecho acima, que reproduz todo o oitavo parágrafo do texto, é novamente um relato de fala, dessa vez de uma moradora, também representada como indivíduo, por seu nome completo e também por funcionalização ("dona de casa"). Mas o que nos interessa é a representação do 'grupo que incomoda', aqui identificado, como no caso do Exemplo (4), por impessoalização e em referência às consequências de sua presença em termos de incomodidade ("gritaria") e insegurança ("vários assaltos").

Esse trecho não acrescenta novas informações na representação que o texto constrói do problema e do grupo. Aliás, é notável a correspondência entre os modos de representação aqui e no sexto parágrafo, a primeira instância de relato de fala de um morador da localidade: "barulheira" se relexicaliza com "gritaria", e "alvo de assalto" se enfatiza com "vários assaltos". Trata-se, portanto, de reforço de modos de representação já texturizados.

Em termos de transitividade, entretanto, há diferença. Tanto o incômodo quanto a insegurança são aqui representados no campo da experiência, já que os processos são 'presenciar' e 'ouvir'. Assim, o grupo, representado em termos das consequências indesejáveis de sua presença, ocupa a posição de Fenômeno em processos experienciais cujo Experienciador é Francisca Félix.

O último parágrafo dessa segunda parte do texto é copiado no próximo exemplo: 
(7) "Eles sentam no muro e ficam fazendo uma bagunça. Depois usam a caixa d'água para tomar banho. E dá também prostitutas. Virou um perigo morar aqui", frisa.

No Exemplo (7), temos cinco orações. Nas três primeiras, seguindo a tendência do texto, o grupo é representado de maneira genérica, sem referência à individualidade de cada um de seus membros, e por pronominalização, na primeira, e por elipse, nas outras duas. Nesses casos, temos uma representação focalizada na ação: aqui, ao contrário do que vimos em exemplos anteriores, o grupo participa da oração na posição de Ator, portanto em posição ativa em processos materiais. Esse fazer no mundo é sintetizado em "uma bagunça" - o que se ressalta é um comportamento inadequado, socialmente reprovável.

A quarta oração, "E dá também prostitutas", cria uma divisão no grupo, linguisticamente realizada por "também", o que indica que essas "prostitutas" não fazem parte do grupo representados nas três orações anteriores. Aqui estamos diante de um processo existencial, se entendemos que "dá também prostitutas" equivale a 'há também prostitutas', em que "prostitutas" classifica-se como Existente, como algo que simplesmente existe, sem que se represente uma ação associada, exceto a ação pressuposta no nome, de prostituir-se.

Por fim, a última oração do trecho realiza um processo relacional, semelhante àqueles com que o texto se inicia, inclusive na própria manchete: 'X virou Y'. Nesse caso, a ênfase é na mudança de estado para uma situação de insegurança, reforçando o foco central do texto: "Virou um perigo morar aqui”. Como já vimos, esse é o problema que conduz a representação.

Aliás, a representação do grupo por abstração, quando atores sociais são representados por meio de uma qualidade a eles atribuída na representação, é recorrente no texto todo, garantindo sua coerência interna. O grupo é referido por meio de substantivos abstratos, como

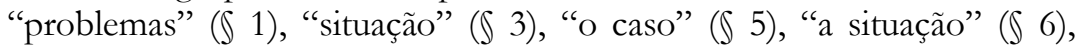
"um perigo" (\$9). Nesses casos, lembremos com van Leeuwen (1997, p. 208), "está a ser-lhes atribuída a qualidade de serem problemáticos, e esta qualidade é usada para os designar". 
Ser classificado como um "problema" e "um perigo" pode servir de justificativa para o expurgo do grupo assimilado como "moradores de rua" e para naturalização da situação de rua. Em trabalho anterior (RESENDE, 2009b), enfatizei que o deslocamento do problema social da situação de rua para suas consequências sobre outros grupos sociais apaga suas consequências sobre a própria população em situação de rua. Quando se focaliza apenas seus efeitos sobre grupos socioeconomicamente incluídos, os devastadores efeitos da pobreza extrema sobre quem de fato os enfrenta deixam de ser percebidos como problema. Não se questiona o fato de seres humanos terem negados seus direitos sociais básicos, mas o "perigo" ou o "problema" que representam para outros grupos.

\section{REFLEXÕES FINAIS OU O QUE NOS RESERVA A TERCEIRA PARTE DO TEXTO}

Uma das funções da mídia, segundo Charaudeau (2010, p. 119), é a regulação do cotidiano social, o que se assegura por meio da dispersão de discursos que "determinam o que são e o que devem ser os comportamentos do corpo social", normatizando as relações sociais em "enquadres de experiência" fundamentados em "avaliações éticas, identificações ou recalques de emoções" que informam o que deve ser compreendido como ordem ou desordem, bom ou ruim, desejável ou indesejável. O mesmo autor relaciona essa função da mídia com o "civil anônimo", interpretado como exemplar da "sociedade em geral", como são Fernando Cardoso e Francisca Félix, que emprestam sua experiência de cidadão e cidadã respeitáveis para uma avaliação de 'grupos incômodos', que precisam ser domesticados nos comportamentos esperados do corpo social, embora seja recalcada qualquer referência a seus direitos negados. O "problema" não é a situação de precariedade em que se encontram, mas sua presença em local específico. Isso faz lembrar o que vimos a respeito da notícia jornalística como gênero de governança, associada ao "aparato de governança" dos meios de comunicação, que podem controlar os eventos noticiados, quando os recontextualizam.

Aliás, essa representação do problema como sendo a presença de pessoas em situação de rua no bairro, e não a situação de rua em si, 
permite que a representação do fato omita o poder público e sua responsabilidade sobre a violência da privação de direitos para a população em situação de rua. Nos termos de van Leeuwen (2008), temos a supressão do ator social Estado. O Ibama é responsabilizado pelo abandono do imóvel, mas o Estado não é mencionado por permitir a apartação entre cidadãos de direitos e populações classificadas como "problema", que não têm direito a ter direitos. ${ }^{2}$

A naturalização da injustiça social faz com que seja percebida como a-histórica, independente de ação política humana. Simplesmente uns tem sorte e outros não, ou, o que é pior, uns são competentes e outros não. Isso se relaciona à falta de mobilização da sociedade, de modo geral, no enfrentamento do problema, e à ausência de abordagem prioritária pelo poder público - se não é uma injustiça, não há por que se indignar. Segundo Dejours (2003, p. 19):

Nem todos partilham hoje do ponto de vista segundo o qual as vítimas do desemprego, da pobreza e da exclusão social seriam também vítimas de uma injustiça. Em outras palavras, para muitos cidadãos, há aqui uma clivagem entre sofrimento e injustiça. Essa clivagem é grave. Para os que nela incorrem, o sofrimento é uma adversidade, mas essa adversidade não reclama necessariamente reação política.

Em outras palavras, o sofrimento alheio somente suscita sentimento de revolta quando é percebido como consequência de injustiça, o que não tem acontecido com relação à situação de rua. Sem dúvida, esta percepção das coisas não é construção individual: decorre de construções discursivas e ideológicas, da naturalização de processos sociais como fenômenos e da legitimação de determinadas posições como sendo justas. Por isso, o enfrentamento das situações de precariedade no Brasil tem de ser necessariamente baseado na ética, em

\footnotetext{
${ }^{2} \mathrm{O}$ termo apartação, conforme Buarque (2001) explica, tem sua origem etimológica na palavra latina partire, cujo conceito refere-se à divisão em partes. O vocábulo latino deu origem, no africâner, ao termo apartheid, na África do Sul. Do conceito de apartheid social, Buarque propôs o termo apartação, como o desenvolvimento separado de segmentos em uma sociedade não em termos de etnias, mas de classes. Buarque (2001, p. 34) esclarece que "o centro do conceito de apartação está em que o desenvolvimento brasileiro não provoca apenas desigualdade social, mas uma separação entre grupos sociais".
}

RESENDE - Representação discursiva de pessoas... 
termos de mudança de prioridades, de estratégia política, de mobilização da sociedade e de pressão sobre o Estado.

Antes de passar a uma breve reflexão sobre a terceira parte do texto, mais uma vez quero ressaltar que há um fio condutor que constrói correspondência entre os 'grupos incômodos' representados "prostitutas", "usuários de drogas" e "meninos de rua", todos unificados pelo generalizador "moradores de rua", que ancora a notícia já na manchete. Embora haja divisões, quando certos grupos são enfatizados em particular, ainda que sempre em referências genéricas, sem foco no indivíduo - por exemplo, "usuários de drogas", que são presos mas voltam, ou prostitutas, que simplesmente existem -, todos esses grupos sociais são assimilados como "moradores de rua", notadamente quando "atrair uma série de moradores de rua" (\$4) parece constituir a retomada generalizante de "virou ponto de encontro de usuários de drogas, prostitutas e meninos de rua" (\1), que por sua vez especifica a referência anterior, na manchete: "virou ponto de drogas e abrigo para moradores de rua".

Então vejamos como termina o texto. $\mathrm{O}$ que nos interessa são os dois parágrafos iniciais da terceira parte, quando se fornece outra informação, pela articulação da voz policial, que subverte a lógica construída na primeira e na segunda partes do texto:

Vigia do posto policial 53 do Lago Norte, o sargento Messias afirma que a casa realmente está abandonada. Lá ele já pegou meninos usuários de drogas. No entanto, diz, a maioria não são meninos de rua e sim os próprios moradores do Lago Norte.

"Os usuários de drogas que pegamos são pessoas de classe média que aproveitam o local deserto para fazer o uso. Realmente é perigoso ter um imóvel vazio. Mas estamos sempre lá atendendo às reclamações", justifica.

Depois de as duas primeiras partes do texto, que ocupam nove dos treze parágrafos da notícia, salientarem repetidas vezes a associação do "problema" com "moradores de rua", agora no final se inclui informação da autoridade policial que contradiz essa lógica: os tais "usuários de drogas" seriam, na verdade, pelo menos em sua maioria, "os próprios moradores do Lago Norte", "pessoas de classe média que aproveitam o local deserto para fazer o uso [de drogas]". 
A introdução dessa informação, em relato indireto da fala do sargento, no décimo parágrafo, utiliza como verbo dicendi "diz" - o que contrasta com as escolhas de verbos dicendi que introduzem as vozes de Fernando Cardoso e Francisca Félix: "indigna-se", "relata", "revolta-se", "frisa". A informação de que o "problema" tem sua origem na própria comunidade é colocada em segundo plano, não só por sua localização ao final do texto, mas também pela diferença de ênfase, se lembrarmos que a associação do "problema" com "moradores de rua" é posta em relevo ao longo do texto. Estaríamos aqui diante do que Charaudeau (2010, p. 119) classificou como "recalque"?

\section{REFERÊNCIAS}

ALEXANDRE, M. F.; RESENDE, V. de M. Representação discursiva da pobreza extrema - análise discursiva crítica de um testemunho publicado em editorial da revista Cais. Revista Latinoamericana de Estudios del Discurso, v. 10, n. 2, p. 87-105, 2010.

ARCHER, M. Being buman. The problem of agency. Cambridge: University Press, 2000.

BHASKAR, R. The possibility of Naturalism: a philosophical critique of the contemporary Human Sciences. Hemel Hempstead : Harvester Wheatsheaf, 1989.

BHASKAR, R. Philosophy and scientific realism. In: ARCHER, M.;

BHASKAR, R; COLLIER, A.; LAWSON, T.; NORRIE, A. (Orgs.). Critical realism: essential readings. London; New York: Routledge, 1998, p. 16-47.

BUARQUE, C. O que é apartação: o apartheid social no Brasil. São Paulo: Brasiliense, 2003.

CHARAUDEAU, P. Discurso das mídias. São Paulo: Contexto, 2010.

DEJOURS, C. A banalização da injustiça social. Rio de Janeiro: FGV Editora, 2003.

FAIRCLOUGH, N. Discurso e mudança social. Trad. (coord.) Izabel Magalhães. Brasília: Universidade de Brasília, 2001.

. Analysing discourse: textual analysis for social research. London; New York: Routledge, 2003.

GOUVEIA, C. A. M. Texto e gramática: uma introdução à linguística sistêmicofuncional. Matraga, v. 24, n. 16, p. 13-47, 2009. 
HALLIDAY, M. An introduction to Functional Grammar. Revisão Christian Matthiessen. London: Hodder Arnold, 2004.

INSP (International Network of Street Papers/Rede Internacional de Jornais de Rua). What is a street paper?. Disponível em: $<$ http://www.street-papers.org $>$. Acesso em: jul. 2011.

MATTOS, R. M.; FERREIRA, R. F. Quem vocês pensam que (elas) são? Representações sobre as pessoas em situação de rua. Psicologia \& Sociedade, v. 16, n. 2, p. 47-58, 2004.

MONTECINO, L. (Org.). Discurso, pobreza y exclusión en América Latina. Santiago: Editorial Cuarto Propio, 2010.

NASCIMENTO, E. P. Dos excluídos necessários aos excluídos desnecessários. In: BURSZTYN, M. (Org.) No meio da rua: nômades, excluídos e viradores. Rio de Janeiro: Garamond, 2003.

ONU (Organização das Nações Unidas). Habitat. 100 million homeless in world. Disponível em:

$<$ http://www.un.org/Conferences/habitat/unchs/press/women.htm>. Acesso em: jul. 2011.

PARDO ABRIL, N. Como hacer análisis crítico del discurso. Una perspectiva latinoamericana. Santiago: Frasis, 2007.

PARDO ABRIL, N. ¿Que nos dicen? ¿Que vemos? ¿Que és... pobreza? Bogotá: Universidad Nacional de Colômbia, 2008.

PARDO, M. L. (Org.). Análisis crítico de los discursos de las personas en situación de pobreza extrema en América Latina, volume monográfico de Discurso \& Sociedad, v. 2, n. 2, 2008a.

2008b. (Org.). El discurso sobre la pobreza en América Latina. Santiago: Frasis,

RAMALHO, V.; RESENDE, V. de M. Análise de discurso (para a) crítica: o texto como material de pesquisa. Campinas: Pontes, 2011.

RESENDE, V. de M.; RAMALHO, V. Análise de Discurso Crítica. São Paulo: Contexto, 2006.

RESENDE, V. de M. Análise de discurso crítica e realismo crítico. Implicações interdisciplinares. Campinas: Pontes, 2009a.

'It's not a matter of inhumanity': a critical discourse analysis of an apartment building circular on 'homeless people'. Discourse \& Society, v. 20, p. 363-379, 2009b. 
SILVA, D. E. G. Representações discursivas da pobreza e discriminação na mídia. In: SILVA, D. E. G. et al. (Orgs.) Discurso em questão. Representação, gênero, identidade, discriminação. Goiânia: Cânone Editoria, 2009, p. 63-74. THOMPSON, J. B. Ideologia e cultura moderna. Teoria social crítica na era dos meios de comunicação de massa. Petrópolis: Vozes, 2002.

VAN LEEUWEN, T. A representação dos atores sociais. In: PEDRO, E. R. (Org.) Análise Crítica do Discurso: uma perspectiva sociopolítica e funcional. Lisboa: Caminho, 1997, p. 169-222.

Discourse and practice: new tools for critical discourse analysis. New York: Oxford, 2008.

Recebido em 17/11/11. Aprovado em: 22/07/12.

Title: Discursive representation of homelessness in "Caderno Brasilia": naturalization and purge Author: Viviane de Melo Resende

Abstract: In this paper, based upon Critical Discourse Analysis I analyze the text "Abandono no Lago Norte - Casa que pertence ao Ibama virou ponto de drogas e abrigo para moradores de rua", published in January 2011 in "Caderno Brasilia", a newspaper distributed for free in bundreds of spots in Brasilia. The analyzed text discusses the abandonment of a public property and its consequences for the neighborhood, with reference to the "bomeless". Taking this analytical object, I proceed to the analysis of the representation of social actors, specifically the group classified as "bomeless" in the text. I also analyze the representation of this group in the Transitivity System. Analyses show that the street situation, a serious contemporary social problem, is naturalized in the representation of the event in focus in the text. Keywords: Critical Discourse Analysis. Representation. Transitivity. Naturalization. Street situation.

Titulo: Representación discursive de personas en situación de calle en el "Cuaderno Brasilia": naturalización y purga del otro

Autor: Viviane de Melo Resende

Resumen: En este artículo, utilizo el referencial del Análisis de Discurso Crítico para analizar el texto "Abandono en el Lago Norte - Casa que pertenece al Ibama se convirtió en punto de drogas y abrigo para sin hogar", publicado en enero de 2011 en el "Cuaderno Brasilia", semanario ligado al periódico Hoy en Dia distribuido gratuitamente en centenas de puntos de Brasilia. El texto discute el abandono de un inmueble público y sus consecuencias para la vecindad, haciendo referencia, inclusive en el subtitulo, a "sin hogar". Tomando ese objeto analitico, procedo al análisis de la representación de actores sociales, especificamente del grupo clasificado como "sin hogar". También analizo, desde el punto de vista de la oración como representación, como ese grupo aparece en el Sistema de Transitividad, con base en las oraciones en que el grupo es representado. El análisis apunta que la situación de la calle, grave problema social contemporáneo, es naturalizada en la representación del evento en foco en el texto.

Palabras-clave: Análisis de Discurso Crítico. Representación. Transitividad. Naturalización. Situación de calle.

RESENDE - Representação discursiva de pessoas... 